\title{
Long-term slow slip events along the Nankai trough subduction zone after the 2011 Tohoku earthquake in Japan
}

\author{
Shinzaburo Ozawa*
}

\begin{abstract}
The global navigation satellite system (GNSS) network in Japan has detected transient crustal deformation in regions along the Nankai trough subduction zone in southwest Japan from approximately 2013, after the 2011 Tohoku earthquake. Using the GNSS data, we estimated the spatiotemporal evolution of long-term aseismic slip along the Nankai trough. The result indicates that aseismic slip has occurred on the plate interface in the Bungo, northern Miyazaki, and southern Miyazaki regions, southwest Japan. The estimated time evolution between October 2013 and April 2015 shows the simultaneous occurrence of northern and southern Miyazaki slow slips with different durations followed by a Bungo slow slip in 2014. A southern Miyazaki slow slip occurred from approximately July 2015, which was followed by a northern Miyazaki slow slip and a Bungo slow slip in 2016. The 2016 Bungo slow slip occurred in a shallow area that did not slip at the time of the 2014 Bungo slow slip. The two different rupture processes from 2013 to 2015 and from 2015 to 2016 may be an important clue toward understanding subduction tectonics in southwest Japan. These interplate slow slip events are changing the stress state in favor of the occurrence of Nankai and Hyuga-nada earthquakes together with Tokai and Kii channel slow slips, which have been occurring since approximately 2013 and 2014, respectively.
\end{abstract}

Keywords: Nankai trough, Shikoku and Kyushu, Bungo, Nankai earthquake, Hyuga-nada earthquake, Long-term slow slip

\section{Background}

Figure 1 shows the tectonic setting of southwest Japan, which consists of the islands of Honshu, Shikoku, and Kyushu. The Philippine Sea plate is subducting beneath southwest Japan from the Suruga and Nankai troughs at an annual rate of approximately $4-7 \mathrm{~cm} /$ year in the northwest direction (e.g., Sella et al. 2002). The estimated upper boundary of the Philippine Sea plate reaches a depth of approximately $40 \mathrm{~km}$ beneath the northern part of Shikoku, while it reaches approximately $120-140 \mathrm{~km}$ beneath the central part of Kyushu (see Fig. 1b). Owing to the subduction of the Philippine Sea plate, southwest Japan has experienced megathrust earthquakes with a time interval of approximately

\footnotetext{
*Correspondence: ozawa-s96sa@mlit.go.jp Geospatial Information Authority of Japan, Kitasato 1, Tsukuba, Ibaraki 305-0811, Japan
}

140 years (see Fig. 1a) (e.g., Kumagai 1996). The latest Tokai earthquake occurred in 1854, while the latest Nankai earthquake occurred in 1946. Thus, the Tokai region is assumed to be a seismic gap with the potential for a moment magnitude $\left(M_{\mathrm{w}}\right) 8$ earthquake to occur, considering the time lapse of approximately 160 years since the 1854 Tokai earthquake. The Nankai trough is also nearing its next earthquake, considering the time lapse of 70 years since the 1946 Nankai earthquake. On the other hand, $M_{\mathrm{w}} 7$-class earthquakes have repeatedly occurred in the Hyuga-nada Sea off Kyushu, southwest Japan, at a time interval of 10-20 years (e.g., Shiono et al. 1980). The last Hyuga-nada earthquakes occurred on October 19 and December 3, 1996, with moment magnitudes of approximately 6.8 and 6.7 (see Fig. 1b) (e.g., Yagi et al. 1999), respectively, indicating the potential for the next Hyuga-nada earthquake in the near future based on a time lapse of 20 years. 


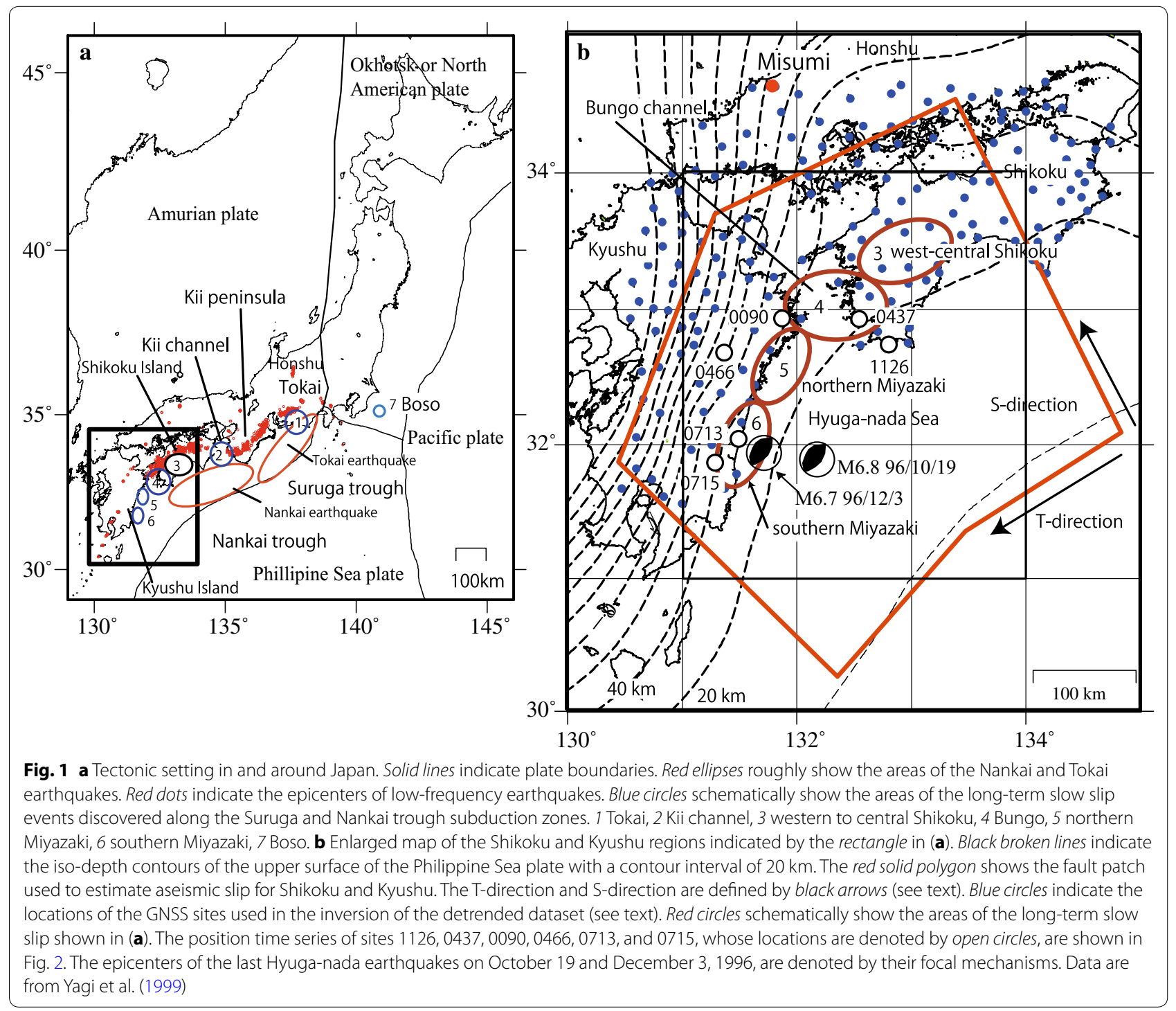

Under these circumstances, the GNSS monitoring network in southwest Japan has revealed a variety of slow slip events segmented along the Suruga and Nankai trough subduction zones. Along these subduction zones, a Tokai slow slip, a Kii channel slow slip, western to central Shikoku slow slips, Bungo slow slips, northern Miyazaki slow slips, and southern Miyazaki slow slips have been discovered (Fig. 1). The Tokai slow slip occurred between 2001 and 2005 (e.g., Ozawa et al. 2002, 2016). The Kii channel slow slip occurred from 1997 to 1998 (Kobayashi 2014). Western to central Shikoku slow slips occurred between 2004 and 2006 and between 2011 and 2013, following the Bungo slow slips (Takagi et al. 2016). The Bungo slow slips (Hirose et al. 1999) have occurred with a time interval of approximately 6 and 1-year duration (e.g., Ozawa et al. 2013). The last Bungo event before the 2011 Tohoku earthquake occurred in 2010. The northern Miyazaki slow slip was first discovered by Yarai and Munekane (2015) and Nishimura and Ochi (2015) to have occurred between 2013 and 2014. After their discovery, GSI proposed that northern Miyazaki slow slip occurred in 1997 from GNSS data (GSI 2015). In the 1997 case, we could also observe aseismic slip in the northern Miyazaki area (Ozawa et al. 2001). Southern Miyazaki slow slips have occurred with an approximately 2-year recurrence interval and 1-year duration (Yarai and Ozawa 2013).

A series of studies also showed the segmentation of rupture areas in the dipping direction near the Bungo channel area, southwest Japan. In this area, ordinary earthquakes occur in a seismogenic zone, while slow slip events occur in the transition area between the shallow locked zone and the deeper unlocked zone. Short-term slow slip events with a duration of several days appear to occur in the deeper part of the above-mentioned transient zone where 
low-frequency earthquakes occur (see Fig. 1a) (Obara 2002), while long-term slow slip events, which last more than several months, occur in the shallower area of the transition zone up-dip of the low-frequency earthquake area (e.g., Hirose and Obara 2005; Ozawa et al. 2013; Takagi et al. 2016). In addition, Yarai and Ozawa (2013) showed that the afterslip and long-term slow slip events occur in a region deeper than the coseismic slip area in the Hyuga-nada region, southwest Japan. We consider only long-term slow slip events in this paper from now.

Long-term slow slip events are very important for assessing the accumulation and release of strain in the subduction processes. Furthermore, long-term slow slip events change the stress state, making it favorable for neighboring earthquakes. That is, we cannot rule out the possibility that long-term slow slip events trigger large earthquakes in nearby seismogenic zones, as was the case of the Papanoa earthquake triggered by a slow slip event in Guerrero, Mexico (Radiguet et al. 2016). The Nankai and Hyuga-nada earthquakes are the assumed large earthquakes in this study. Thus, it is necessary to analyze and monitor long-term slow slip events in southwest Japan.

With this background, the GNSS network in Japan has detected transients along the Suruga and Nankai trough subduction zones from approximately 2013, after the 2011 Tohoku earthquake (Ozawa et al. 2011). In this study, we estimate the spatiotemporal evolution of the interplate coupling in Shikoku and Kyushu using the GNSS data from 2013, after the 2011 Tohoku earthquake, by applying a time-dependent inversion technique.

\section{Methods}

GNSS data were analyzed by Bernese GNSS software (version 5.0) to obtain daily positions. We used the F3 solution (Nakagawa et al. 2008), which is based on the final orbit and earth rotation parameters of the International GNSS Service (IGS) and has a high S/N ratio. We transformed the F3 solution to the east-west (EW), north-south (NS), and up-down (UD) position time series at GNSS sites in Honshu, Shikoku, and Kyushu.

In the process of obtaining the detrended position time series, we first estimated annual components separately in the EW, NS, and UD raw position time series at each station using a polynomial function that corresponds to the trend component and trigonometric functions that correspond to the periodic annual components for the data from January 1, 2012, to April 10, 2016. That is, we fit the following function to raw position time series.

$$
Y(t)=\sum_{i=0}^{n} A_{i} t^{i}+\sum_{i=1}^{m} B_{i} \sin (2 \pi i t)+\sum_{i=1}^{m} C_{i} \cos (2 \pi i t)
$$

Here, $\mathrm{Y}(t)$ is the raw position time series, $t$ is time, $A_{i}$ are the coefficients of the polynomial function, and $B_{i}$ and $C_{i}$ are the coefficients of the trigonometric functions. The reason why we chose the data before April 10, 2016, is that the 2016 Kumamoto earthquakes occurred from April 14, 2016 (e.g., Asano and Iwata 2016), the coseismic and postseismic slips of which contaminated the subsequent GNSS data.

The degree $\mathrm{n}$ of the polynomial function and the overtone $\mathrm{m}$ of the trigonometric functions were estimated from Akaike's information criterion (AIC) (Akaike 1974) (Additional file 1). $n$ ranges from approximately 10-30 and $m$ ranges from approximately $2-20$ in this study, depending on the position time series. After removing the annual components from the raw position time series, we fitted the linear trend for the data between January 1, 2012, and March 1, 2013, during which there were no transient displacements, and removed it from the data that have no annual components. The reason why we used a longer period than the trend period to estimate the annual components is that annual components are more precisely estimated by using data obtained over a longer period. However, as the time period increases longer, the trend component becomes nonlinear. Thus, we first fitted a polynomial function and trigonometric functions to estimate annual components and after that we removed the steady-state velocity. The original position time series and detrended time series at two selected GNSS sites are shown in Additional file 2.

We evaluated the stability of the estimated linear trend. Loveless and Meade (2010) used the trend for the period between 1997 and 2000. Since we know that the central and southern parts of Kyushu island were affected by postseismic deformation after the 1996 Hyuga-nada earthquakes and that northern Kyushu and southwest Shikoku were affected by the 1997 Bungo slow slip, we estimated the trend for the period between 1998 and 2000. In addition, we also checked the trend estimated for a different period between 2000 and 2002. We compared the resulting trends at six GNSS sites (Table in Additional file 3). The result shows similar horizontal trends at the GNSS sites in southwest Shikoku and northern Kyushu with differences approximately within one standard deviation among three periods. With regard to central and southern Kyushu, the GNSS sites show at most $1-\mathrm{cm} /$ year difference between the period of this study and 1998-2000, while the trend between 2000 and 2002 shows differences within one standard deviation from the trend in this study. We consider that the above differences of $1-\mathrm{cm} /$ year between the trend in this study and that for 1998-2000 are due to the postseismic deformation after the 1996 Hyuga-nada earthquakes. Thus, we think that the adopted trend in this study well represents 
the approximate steady state in this region, considering the similarities among the three periods.

Since our focus in this study is on events with a time duration of less than 1 year, we assume that the above small differences in the long-term trend do not significantly affect the following results. Furthermore, we consider that the steady state for the period of this study is effective for emphasizing the results because the Bungo, northern Miyazaki, and southern Miyazaki slow slips clearly appeared as deviations from this steady state. Using these detrended data, we smoothed the position time series by averaging over three days to reduce the errors. We use this dataset as the detrended dataset in the following analysis.

We applied square-root information filtering (Ozawa et al. 2012) to the detrended position time series at 185 GNSS sites in Honshu, Shikoku, and Kyushu (see Fig. 1b) following the network filtering technique of McGuire and Segall (2003) for the period between January 1, 2013, and April 10, 2016. To reduce the computational burden, we used position time series every 3 days. We weighted the EW, NS, and UD displacements with a ratio of $1: 1: 1 / 3$, which is from the standard deviations derived by ordinary Kalman filtering.

We adopted a fault patch along the Nankai trough as shown in Fig. 1b. This fault patch and the slip distribution on this fault patch consist of the superposition of spline functions (Ozawa et al. 2001). The adopted fault patch has 26 nodes in the T-direction and 15 nodes in the S-direction (Ozawa et al. 2001), as defined in Fig. 1b. The spacing among the nodes on the fault patch is roughly $20 \mathrm{~km}$. We used the plate boundary model of Hirose et al. (2008). The coefficients of the spline functions that constitute the slip distribution on the fault patches were estimated in this inversion (Ozawa et al. 2001).

In this filtering analysis, we adopted a state $(u, v)$, where $u$ represents slip and $v$ represents slip velocity (Ozawa et al. 2001). We used the inequality constraint that the slip direction is within $40^{\circ}$ of the direction opposite the motion of the Philippine Sea plate following the method of Simon and Simon (2006). We also constrained the spatial roughness of the slip velocity (McGuire and Segall 2003). We used the roughness matrix $M$ defined in Ozawa et al. (2001). In this case, $\mathrm{uM}^{\mathrm{T}} \mathrm{Mu}$ approximately represents the integral of the square of the Laplacian of the slip $u$ on the fault surface (Ozawa et al. 2001). We incorporated $\lambda M\left(u_{n+1}-u_{n}\right) / \Delta t=0$ and $\lambda M\left(v_{n}\right)=0$ in the transition equation of the square-root information filter, where $\lambda$ is a spatial hyperparameter, $\Delta t$ represents the time from step $n$ to step $n+1, u_{n+1}$ represents the predicted slip at step $n+1, \mathrm{u}_{n}$ represents the slip at step $n$, and $v_{n}$ represents the slip velocity at step $n$. The temporal smoothness hyperparameter $\tau$ was described in Ozawa et al. (2001). These spatial and temporal hyperparameters $\lambda$ and $\tau$ were estimated by approximately maximizing the log likelihood of the system (Additional file 4) (Kitagawa and Gersch 1996; McGuire and Segall 2003). The squares of the optimal $\lambda$ and $\tau$ are approximately $10 \mathrm{~m}^{2} \mathrm{~d}^{2}$ and 14 $\mathrm{m}^{2} \mathrm{~d}^{-3}$, respectively, where $\mathrm{m}$ is meter and $\mathrm{d}$ is day.

\section{Results and discussion}

The detrended crustal deformation data show eastward, southeastward, and southward displacements in Shikoku and Kyushu with respect to the Misumi site (see Fig. 1b). The time evolution of these displacements can be clearly observed in the detrended position time series of selected GNSS sites (Fig. 2). Sites 1126 and 0437, respectively, show southeastward transients for 2014 and from early 2016. Site 1126 shows slight uplift from early 2016, while site 0437 shows uplift in the middle of 2014. These transients indicate aseismic slip in southwestern Shikoku and the Bungo channel region. Site 0090 shows eastward movement for 2014, indicating aseismic slip near this area. Site 0466 shows southeastward transients from late 2013 to late 2014 and from early 2016, suggesting the occurrence of slow slip in northern Miyazaki prefecture. Sites 0713 and 0715 , respectively, show southeastward and southward displacements between late 2013 and the middle of 2014 and from the middle of 2015 . The southward transient observed at 0715 is caused by the southern Miyazaki slow slip in this area (Yarai and Ozawa 2013).

Figure $3 \mathrm{a}-\mathrm{g}$ shows the time evolution of the spatial pattern of the detected transients. Figure $3 \mathrm{~b}$ shows southeastward transients in the northern and central parts of Kyushu and southward transients in the southern coastal area of Kyushu between October 1, 2013, and May 1, 2014, suggesting the occurrence of aseismic slip on the plate interface in the northern Miyazaki and southern Miyazaki regions (Yarai and Ozawa 2013). Figure 3c shows clear transients in the central to northern parts of Kyushu and in southwestern Shikoku between May 1, 2014, and October 1, 2014. After the decay of transients between October 1, 2014, and April 1, 2015 (Fig. 3d), eastward transients in the southern coastal area of Kyushu appear between April 1, 2015, and July 1, 2015 (Fig. 3e). However, we cannot clearly say that this is a real signal since these eastward transients are very large at only one GNSS site. The small southward transients in the coastal area of southern Kyushu between July 1, 2015, and February 1, 2016, indicate aseismic slip in the southern Miyazaki area as mentioned above (Fig. 3f). We can clearly see southeastward transients in Kyushu and southwestern Shikoku from February 1, 2016, to April 10, 2016 (Fig. 3g). These transients suggest the occurrence of aseismic slip off Kyushu and Shikoku along the Nankai trough subduction zone. 

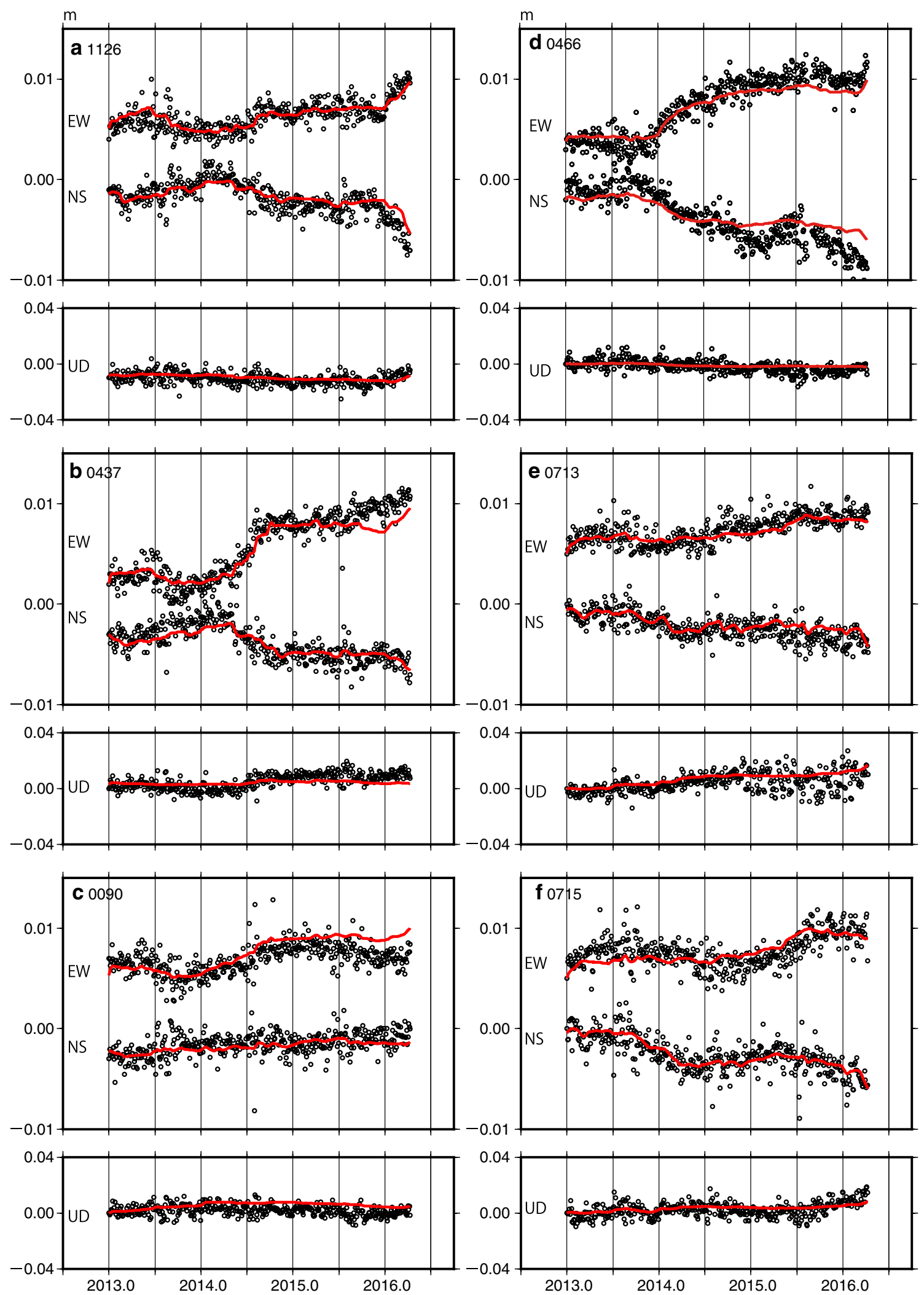

Fig. 2 Detrended position time series (see text) at selected GPS sites. The locations of the GPS sites are shown in Fig. 1b. EW, NS, and UD indicate east-west, north-south, and up-down components, with eastward, northward, and upward positive, respectively. Red lines show values computed by our best-fitting interplate aseismic slip model. The unit is meters. a Site 1126. b Site 0437. c Site 0090. d Site 0466. e Site 0713. f Site 0715 


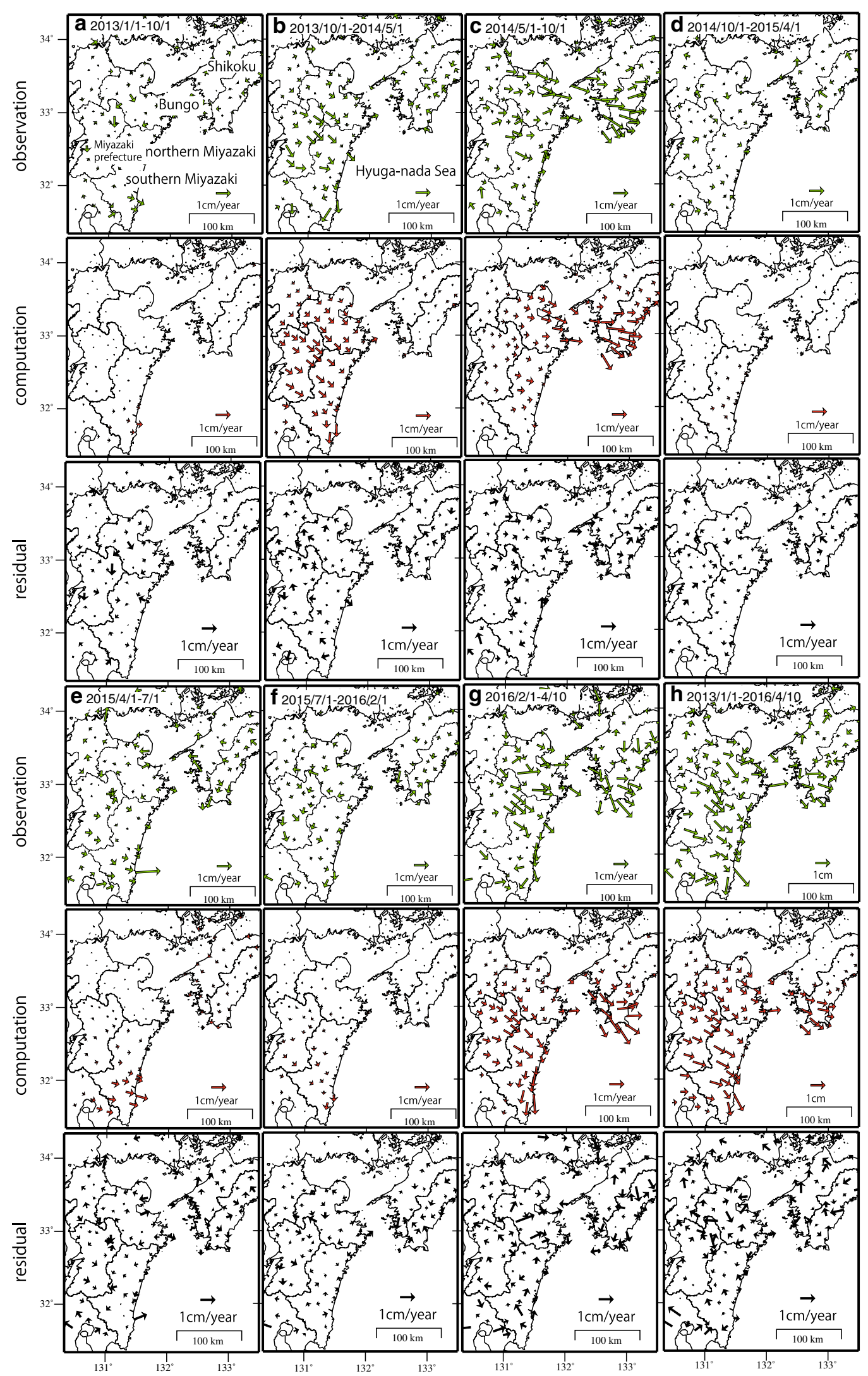


(See figure on previous page.)

Fig. 3 Observed horizontal detrended crustal deformation, computed deformations, and residuals in Shikoku and Kyushu obtained from our bestfitting aseismic slip model. Green arrows in the top figure indicate the observed detrended crustal deformation, while red arrows in the middle figure indicate the computed crustal deformation. Black arrows in the bottom figure indicate residuals. $\mathbf{a}-\mathbf{g}$ The deformation rate and $\mathbf{h}$ the total crustal deformation. Thin solid lines indicate prefectural boundaries in Japan. The other nomenclature is the same for the top, middle, and bottom figures. a January 1, 2013-October 1, 2013. b October 1, 2013-May 1, 2014. c May 1, 2014-October 1, 2014. d October 1, 2014-April 1, 2015. e April 1, 2015July 1, 2015.f July 1, 2015-February 1, 2016. g February 1, 2016-April 10, 2016. h Total detrended crustal deformation observed (top), computed (middle), and residuals (bottom) for the period between January 1, 2013, and April 10, 2016

Figure 3h shows the characteristic features of the spatial patterns of the detrended ground displacements between January 1, 2013, and April 10, 2016. In this figure, we can observe eastward, southeastward, and southward crustal deformation in Shikoku and Kyushu as mentioned above, strongly indicating the occurrence of aseismic interplate slip in these regions. The $1 \sigma$ error is $1-2 \mathrm{~mm}$ for the horizontal displacements in Fig. 3h, as estimated by ordinary Kalman filtering. Thus, the observed transients in Fig. $3 \mathrm{~h}$ exceed the $1 \sigma$ error.

On the basis of the observed detrended displacements, our filtering analysis shows slow slip areas offshore of Shikoku and Kyushu and in the Bungo area. Figure 4b shows the slow slip offshore of southern Miyazaki and northern Miyazaki between October 1, 2013, and May 1, 2014. The aseismic interplate slip for this period ranges from $4 \mathrm{~cm} /$ year in southern Miyazaki to $8 \mathrm{~cm} /$ year in northern Miyazaki. This result is consistent with the results of Yarai and Munekane (2015) and Nishimura and Ochi (2015), although they did not investigate the spatiotemporal evolution. The slip rate between May 1, 2014, and October 1, 2014, offshore of southern Miyazaki and northern Miyazaki decreased and slow slip appeared in the Bungo channel (Fig. 4c). We refer to this slow slip in the Bungo channel as the 2014 Bungo slow slip from now. We can observe the remainder of the slow slip off northern Miyazaki in Fig. 4d, which had a long duration compared with the southern Miyazaki slow slip, which subsided during this period. From April 1, 2015, to July 1, 2015, a slow slip area appeared in and off the southern Miyazaki coastal area of Kyushu. However, the aseismic slip off the southern Miyazaki area is less certain, since this large slow slip is based on a large eastward transient observed at one GNSS site, the slow slip area is far offshore, and the ground displacement data are insufficient to support the existence of the slow slip this far offshore (Fig. 4e). The aseismic interplate slip rate between July 1, 2015, and February 1, 2016, was over $8 \mathrm{~cm} /$ year off the southern Miyazaki coast (Fig. 4f). Aseismic interplate slip rates of approximately $8 \mathrm{~cm}$ /year off the southern Miyazaki coast and $12 \mathrm{~cm} /$ year in southwestern Shikoku occurred between February 1, 2016, and April 10, 2016. We refer to this aseismic slip event in southwestern Shikoku as the 2016 Bungo slow slip from now. The slow slip area in the southern Miyazaki area expanded northward to the northern Miyazaki area during this period. Although the estimated slip for this period is near the limit of the $1 \sigma$ error in northern Miyazaki, we assume that the estimated slip in northern Miyazaki actually occurred, considering the estimated ground displacements in Figs. 2d and 3g. Figure $4 \mathrm{~h}$ shows the estimated total slip for the entire period. We can see a slow slip off Kyushu and Shikoku. The aseismic slip off southern Miyazaki reaches $12 \mathrm{~cm}$ and that off northern Miyazaki reaches $8 \mathrm{~cm}$. Since Fig. $4 \mathrm{~h}$ shows the total slip and not the slip rate, the image of the aseismic slips is slightly different from those in Fig. 4a-g. Because of the coseismic and postseismic deformation due to the 2016 Kumamoto earthquakes, we cannot observe further time evolution after April 14, 2016.

Figure $4 \mathrm{i}-\mathrm{p}$ shows the $1 \sigma$ error of the estimated aseismic slip rate and aseismic slip corresponding to Fig. 4ah. The contour interval is $4 \mathrm{~mm} /$ year in Fig. $4 \mathrm{i}, 1 \mathrm{~cm} /$ year in Fig. $4 \mathrm{j}-\mathrm{O}$, and $1 \mathrm{~cm}$ in Fig. $4 \mathrm{p}$, indicating that the estimated interplate slip rates and the total slip for the entire period are larger than the $1 \sigma$ error, although the aseismic slip rate between February 1, 2016, and April 10, 2016, slightly exceeds the $1 \sigma$ error as mentioned above.

Thus, southern Miyazaki slow slips occurred from late 2013 to the middle of 2014 and from the middle of 2015 with a recurrence interval of approximately 2 years during the period of this study. This recurrence interval is consistent with the past southern Miyazaki slow slip events (Yarai and Ozawa 2013), although we cannot clearly state that the southern Miyazaki slow slip occurred in 2011, 2 years after the 2009 southern Miyazaki slow slip, because of the contamination of the 2011 Tohoku earthquake. The maximum estimated slip of the southern Miyazaki slow slip in this study for the two events is roughly $12 \mathrm{~cm}$. In Yarai and Ozawa (2013), the maximum slippage of the slow slip events in this area is approximately $5 \mathrm{~cm}$. Since the slip deficit rate is not well determined in this area, we roughly estimated slip deficit rates in this area by applying Yabuki and Matsu'ura's method (1992) to the trend velocity estimated in this study (Additional file 5). The maximum accumulated slip deficit is approximately $4 \mathrm{~cm} /$ year in the southernmost segment in Fig. 4h, corresponding to the southern Miyazaki slow slip area. The moment of the slip deficit for the period of 


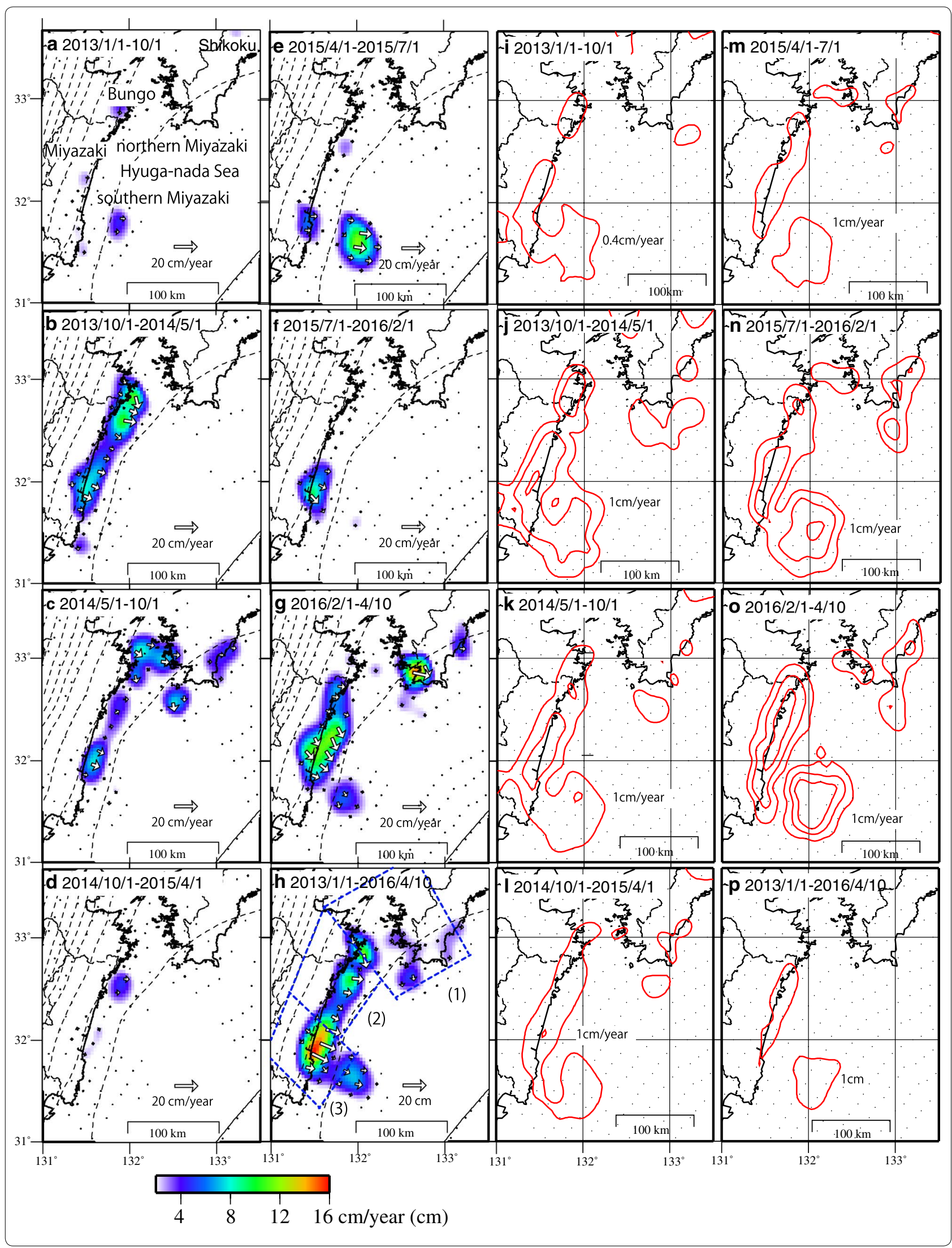


(See figure on previous page.)

Fig. 4 a Estimated aseismic slip rate on the interface between the Amurian plate and the Philippine Sea plate based on the detrended dataset for the period between January 1, 2013, and October 1, 2013, with the unit of $\mathrm{cm} /$ year. The white arrow also indicates the estimated aseismic slip. The dashed lines indicate iso-depth contours of the plate interface with an interval of $20 \mathrm{~km}$ (Hirose et al. 2008). Thin solid lines indicate prefectural boundaries in Japan. b October 1, 2013-May 1, 2014. c May 1, 2014-October 1, 2014. d October 1, 2014-April 1, 2015. e April 1, 2015 -July 1, 2015. f July 1, 2015-February 1, 2016. g February 1, 2016-April 10, 2016. h Total slip between January 1, 2013, and April 10, 2016, with the unit of cm. The moment magnitudes of the three areas (1)-(3) separated by blue dashed lines are computed as the Bungo, northern Miyazaki, and southern Miyazaki slow slips in Fig. 6 and Additional file 6. The numbers of earthquakes within $5 \mathrm{~km}$ from these three segments are indicated in Additional file 6. i-p Estimated $1 \sigma$ error for the periods corresponding to $(\mathbf{a}-\mathbf{h})$. The contour interval is (i) $4 \mathrm{~mm} /$ year, (j-o) $1 \mathrm{~cm} /$ year, (p) $1 \mathrm{~cm}$

this study in the same segment is roughly $15 \times 10^{18} \mathrm{Nm}$, and the moment released by the detrended aseismic slip in this study for the period between January 2013 and April 2016 is $12 \times 10^{18} \mathrm{Nm}$. Thus, this area may release most of the accumulated slip deficit energy by slow slip events with a 2-year recurrence interval. We estimated the seismic slip by summing those of earthquakes with a magnitude of over 2.0 catalogued by Japan Meteorological Agency whose hypocenters were within $5 \mathrm{~km}$ from the southernmost segment shown in Fig. 4h. In this calculation, we assumed that the earthquakes within $5 \mathrm{~km}$ from the southernmost segment in Fig. 4h were low-angle thrust earthquakes on the plate interface. Thus, this value is a maximum estimate. The estimated seismic moment is $1.8 \times 10^{15} \mathrm{Nm}$, corresponding to that of an $M_{\mathrm{w}} 4.1$ earthquake, and is very small compared with the detrended aseismic slip of $11 \times 10^{18} \mathrm{Nm}$. That is, aseismic slip, consisting of slow slip events and secular tectonic loading, and the postseismic slip of earthquakes dominate over seismic moments in this segment. We think that the Hyuga-nada earthquakes release the remaining loading energy or slip deficit energy in this segment.

Since the time duration of a southern Miyazaki slow slip is approximately 1 year (Yarai and Ozawa 2013), we cannot rule out the possibility that the southern Miyazaki slow slip from 2015 will end soon.

We consider that the aseismic slip in northern Miyazaki is an independent slow slip event since the southern Miyazaki slow slip has occurred independently with a 2-year recurrence interval (Yarai and Ozawa 2013). The estimated slow slip in northern Miyazaki appears to have started in early 2016, approximately $2-3$ years after the 2013 northern Miyazaki slow slip between late 2013 and late 2014. It remains to be examined by detailed studies of the aseismic slip history in northern Miyazaki whether or not this recurrence interval of 2-3 years is consistent with those of the past events. Within the period of this study, the estimated aseismic slip of northern Miyazaki is approximately 4-8 cm, which amounts to half to one year of the slip deficit in this region, considering a maximum slip deficit rate of approximately $8 \mathrm{~cm} /$ year (Additional file 5 ). The estimated moment of the detrended aseismic slip on the middle segment of Fig. $4 \mathrm{~h}$ denoted by blue dashed line is
$9 \times 10^{18} \mathrm{Nm}$ in this study period and that of the slip deficit is $32.0 \times 10^{18} \mathrm{Nm}$ for the same period. Thus, roughly $30 \%$ of the accumulated energy from plate loading was released by aseismic slip in this region during this study period. The estimated seismic moment, which is the sum of those from earthquakes within $5 \mathrm{~km}$ of the middle segment shown in Fig. $4 \mathrm{~h}$ by the blue dashed lines, as for the case of the southern Miyazaki segment, is approximately $1.4 \times 10^{15} \mathrm{Nm}$ and equivalent to that of an $M_{\mathrm{w}} 4.0$ earthquake. Thus, we think that the aseismic slip dominates over seismic slips in this segment. The energy balance indicates the possible existence of an earthquake to release the remaining plate loading energy in this segment independently or as part of the Nankai earthquake. The duration of the 2013 northern Miyazaki slow slip was approximately 1 year. Thus, we cannot rule out the possibility that the latest slow slip in northern Miyazaki from early 2016 is still continuing, although we cannot monitor it because of the strong contamination caused by the 2016 Kumamoto earthquakes.

The 2014 Bungo slow slip was occurring between May 1, 2014, and October 1, 2014 (Fig. 4c), following the southern and northern Miyazaki slow slips (Fig. 4b). This slow slip was very small compared with the 1997, 2003, and 2010 Bungo slow slips, whose slippage was one order larger, suggesting that this event was a different type of slow slip (Ozawa et al. 2013). The 2016 Bungo slow slip occurred in an area where the aseismic slip was small during the 2014 Bungo slow slip in this study. In particular, the main slip area between February 1, 2016, and April 10, 2016, was shallower than that of the 2014 Bungo event. This aseismic slip area in southwestern Shikoku in 2016 slipped during the 1997, 2003, and 2010 Bungo slow slips, whose durations were approximately 1 year, at an early stage of the slip history (Ozawa et al. 2013). If the 2016 Bungo slow slip is of the same type as the 1997, 2003, and 2010 Bungo slow slips, which occurred with a time interval of 6 years, we can assume that the slip has moved to the Bungo channel over time, as was the case for these past long-term Bungo slow slips (Ozawa et al. 2013). The interval between the 2010 and 2016 Bungo slow slips was approximately 6 years, consistent with the interval between past Bungo slow slip events, although we need more data to confirm that the 2016 Bungo slow slip is of the same type as the past Bungo slow slips. Regarding the slip 
budget, the slippage of the Bungo slow slip events ranged from approximately $20-30 \mathrm{~cm}$ before the Tohoku earthquake. Since the slip deficit rate is approximately $6 \mathrm{~cm} /$ year in this region (Additional file 5), the slip deficit amounts to $36 \mathrm{~cm}$ for a 6-year recurrence interval, which approximately satisfies slip budget in part of the denoted segment in Fig. 4h. The accumulated loading energy is $23 \times 10^{18} \mathrm{Nm}$ for 1 year, equivalent to that of an $M_{\mathrm{w}} 6.8$ earthquake. The aseismic slip moment for the period between January 2013 and April 2016 of this study was approximately $6 \times 10^{18} \mathrm{Nm}$ equivalent to that of an $M_{\mathrm{w}} 6.4$. Thus, we think that approximately $8 \%$ of the accumulated slip deficit in the Bungo area was released by slow slips during the period of this study. The seismic moment, which is the sum of those of earthquakes within $5 \mathrm{~km}$ from the northernmost segment in Fig. $4 \mathrm{~h}$, is roughly $2 \times 10^{14} \mathrm{Nm}$ and equivalent to that of an $M_{\mathrm{w}} 3.5$ earthquake. Thus, this Bungo slow slip with a recurrence interval of 6 years that is one order of magnitude larger than the Bungo slow slip in this study may release the remaining loading energy in part of this region together with short-term slow slip events. We cannot rule out the possibility of the occurrence of an earthquake to release the remaining loading energy in this segment independently or as part of the Nankai earthquake.

We consider that the recurrence interval of the southern Miyazaki slow slip events is within the range of fluctuation of those of the past slow slip events. With regard to the Bungo and northern Miyazaki slow slip events, more data and detailed studies are necessary to assess the changes in their recurrence interval.

We also estimated the relationship between the moment release of the three segmented areas denoted by blue dashed lines in Fig. $4 \mathrm{~h}$ and the number of earthquakes with a magnitude over 2.0 that occurred within $5 \mathrm{~km}$ from the plate interface for the three segments, corresponding to the Bungo, northern Miyazaki, and southern Miyazaki areas (Additional file 6). Low-frequency earthquakes are included in the number of earthquakes. However, we could not find a clear correlation between the number of earthquakes and the moment of the aseismic slip, indicating that they are not driving each other in these segments for the period in this study.

The 2011 Tohoku earthquake, together with its postseismic deformation, caused significant crustal deformation in the entire area of Japan. The stress states before and after the Tohoku earthquake appear to be different throughout Japan. This perturbation due to the Tohoku earthquake provides us with a good opportunity to elucidate the subduction processes in southwest Japan. Regarding this point, we expected that the slow slip activity would have been affected by the Tohoku earthquake and its postseismic deformation. In fact, the recurrence interval of the Boso slow slips (Fig. 1a) in Japan changed after the Tohoku earthquake (Ozawa 2014). However, in this study, the effect of the 2011 earthquake on the southern Miyazaki slow slip appears to have been small. If the 2011 Tohoku earthquake also did not affect the occurrence of the Bungo and northern Miyazaki slow slip events, this will give us important information about the stability of the factors triggering these slow slip events. From this viewpoint, it is very important to investigate any differences in the recurrence interval and magnitude of the Bungo and northern Miyazaki slow slips before and after the Tohoku earthquake.

Regarding the relationship among the Bungo, northern Miyazaki, and southern Miyazaki slow slips for the period of this study, we found two different rupture processes. The first involved the time evolution of the aseismic slip from 2013 to 2015, showing that the northern Miyazaki and southern Miyazaki slow slips occurred simultaneously, followed by the Bungo slow slip, with the northern Miyazaki slow slip having a longer duration than the southern Miyazaki slow slip. In the second rupture process from 2015 to 2016, the southern Miyazaki slow slip occurred first, followed by the northern Miyazaki slow slip and the Bungo slow slip. In each case, the rupture process expanded from the south to the north of the slow slip area. We cannot rule out the possibility that the rupture processes among the slow slips in these three regions were affected by each other in this period. That is, the southern Miyazaki and northern Miyazaki slow slips may have prompted the occurrence of the Bungo slow slip in the first rupture process from 2013 to 2015, although the maximum change in the Coulomb failure stress $(\triangle \mathrm{CFS})$ in the Bungo channel area was only approximately $0.01 \mathrm{MPa}$, assuming a rigidity of 30 GPa, Poisson's ratio of 0.25 , and a friction coefficient of 0.2 (Harris 1998) (Additional file 7). Although $\triangle \mathrm{CFS}$ is near the threshold value of $0.01 \mathrm{MPa}$, we cannot rule out the possibility of a large change in stress in the boundary region adjacent to the aseismic slip area of the northern Miyazaki slow slip. In the second process from 2015 to 2016, the southern Miyazaki slow slip may have triggered the northern Miyazaki slow slip. Although $\triangle \mathrm{CFS}$ is approximately $0.00003 \mathrm{MPa}$ in the Bungo channel area and at most $0.004 \mathrm{MPa}$ in the northern Miyazaki area (Additional file 7), we cannot rule out this possibility, since the northern Miyazaki area is adjacent to the southern Miyazaki slow slip area and may be strongly affected by it in the boundary region.

In addition, we calculated $\triangle \mathrm{CFS}$ near the large interplate earthquake area from the total aseismic slip and found out that the slow slip events in this study period increased $\triangle$ CFS. In particular, the area of the 1996 Hyuga-nada earthquakes has a value of $\triangle \mathrm{CFS}$ of up to approximately $20 \mathrm{kPa}$ (Additional file 7). 
Figure 5 shows the time evolution of the moment release. We can observe the fluctuating time evolution of the moment. The periods denoted by the vertical lines correspond to those of the snapshots in Figs. 3 and 4. The estimated total moment is approximately $30 \times 10^{18} \mathrm{Nm}$, which is approximately equivalent to that of an $M_{\mathrm{w}} 6.9$ earthquake.

The displacements computed from our best-fitting aseismic slip model closely reproduce the observed crustal deformation, as shown in Figs. 2 and 3.

\section{Conclusions}

In this study, we investigated the spatiotemporal evolution of the interplate aseismic slip along the Nankai trough subduction zone between 2013 and 2016. The estimated rupture process between 2013 and 2015 followed a different time sequence and time evolution from those between 2015 and 2016. A future work is to determine the spatiotemporal evolution of the slow slip events in the regions in this study before 2013 and compare them with those after 2013, although the data shortly after the Tohoku earthquake are strongly contaminated. For this purpose, we schematically summarize the spatiotemporal long-term slow slip events along the Nankai trough in Fig. 6 together with the approximate moment magnitudes. As mentioned above, we can observe quasiperiodic slow slip activities in Fig. 6, such as the Bungo and southern Miyazaki slow slips. We need to further investigate the spatiotemporal evolution schematically shown in Fig. 6, including whether or not there are any differences before and after the 2011 Tohoku earthquake.

The concept of a seismic gap may hold for the Bungo slow slip for the period of this study because of the clear spatial separation between the 2014 and 2016 events, although we cannot observe further time evolution of the 2016 Bungo slow slip owing to the 2016 Kumamoto earthquakes.

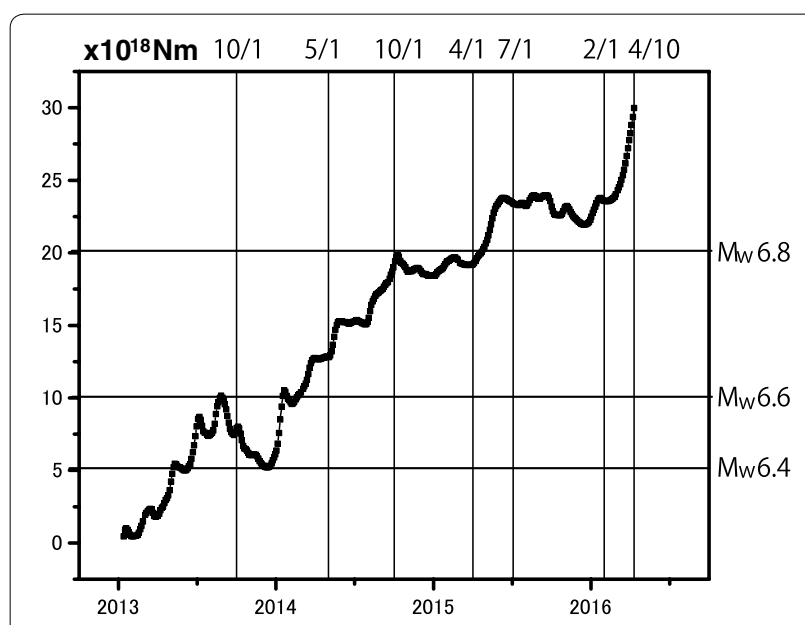

Fig. 5 Estimated time evolution of moment release. The periods denoted by vertical lines correspond to those in Figs. 3 and 4

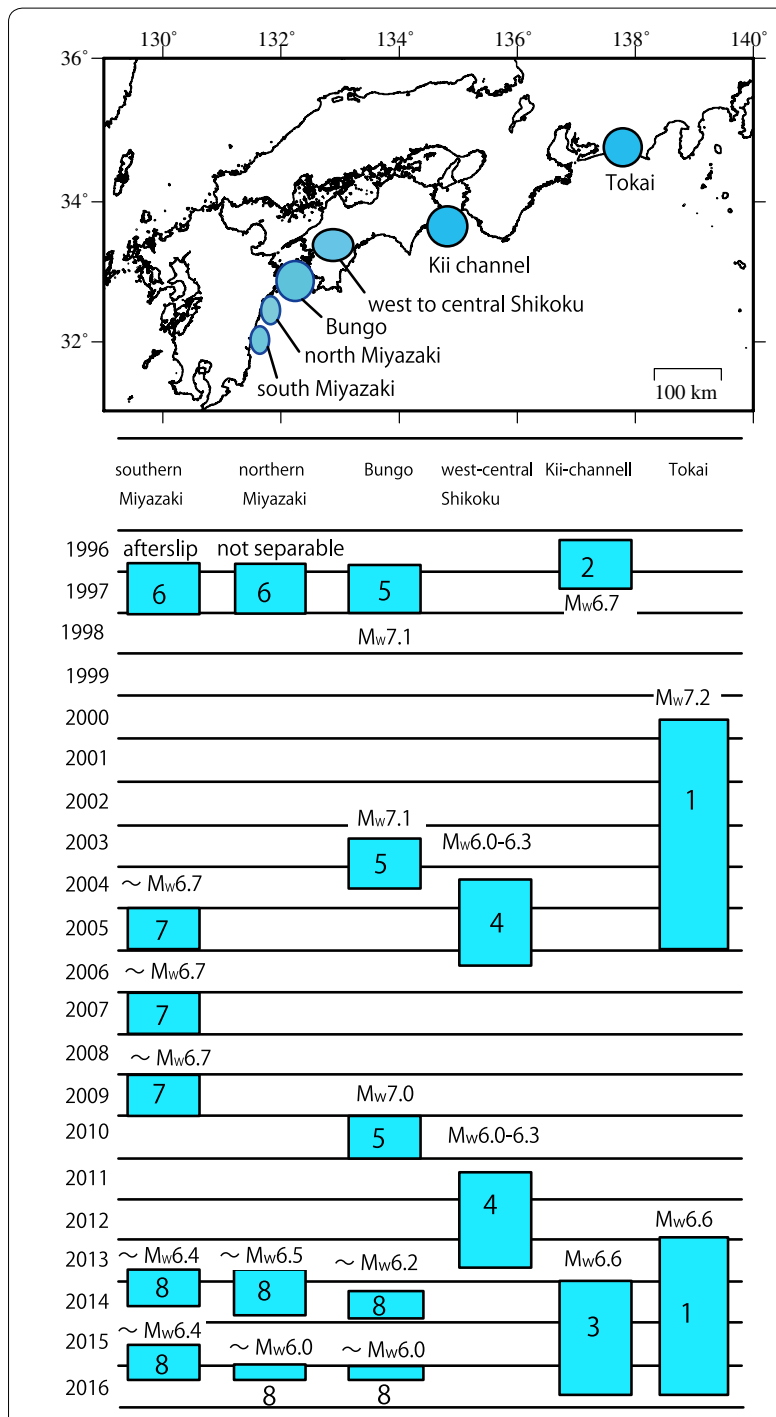

Fig. 6 Schematic spatiotemporal distribution of long-term slow slip events along the Suruga and Nankai troughs together with the moment magnitudes. 1: Tokai (Ozawa et al. 2016), 2: Kii channel (Kobayashi 2014), 3: Kii channel (GSI 2016), 4: western to central Shikoku (Takagi et al. 2016), 5: Bungo (Ozawa et al. 2013), 6: northern Miyazaki and southern Miyazaki (Ozawa et al. 2001), 7: southern Miyazaki (Yarai and Ozawa 2013), 8: Bungo, northern Miyazaki, and southern Miyazaki (this study). The 1997 southern Miyazaki slow slip is interpreted as an afterslip of the 1996 Hyuga-nada earthquakes. With regard to the 1997 northern Miyazaki slow slip, we cannot estimate the moment magnitude since it is not separable from the afterslip of the 1996 Hyuga-nada earthquakes and the 1997 Bungo slow slip. The moment magnitudes of the Bungo slow slip, northern Miyazaki slow slip, and southern Miyazaki slow slip in this study range from $M_{w} 6.0$ to $M_{w} 6.5$. However, these values were estimated by summing the slow slips in their approximate regions, which are shown in Fig. 4h. Thus, the estimated moment magnitudes of the Bungo, northern, and southern Miyazaki slow slips in this study are very approximate since we cannot clearly separate the events in time and space. The values of the moment magnitude of the southern Miyazaki slow slip obtained by Yarai and Ozawa (2013) are also rough estimates since we cannot clearly separate the southern Miyazaki slow slip in the time and space domains 
It is proposed that Tokai and Kii channel slow slips have also occurred from approximately 2013 and 2014, respectively (see Fig. 6) (Ozawa et al. 2016; GSI 2016). Thus, the Bungo, northern Miyazaki, and southern Miyazaki slow slips have been weakening the interplate coupling along the Nankai trough subduction zone since approximately the middle of 2015, when the latest southern Miyazaki slow slip was clearly detected, together with the Tokai and Kii channel slow slips. That is, the slow slip events of this study are changing the stress state in favor of the occurrence of Nankai and Hyuga-nada earthquakes as mentioned in the discussion, whose probability is high considering the time since the last earthquakes. It is an urgent task to continue monitoring the transient crustal deformation in these regions.

\section{Additional files}

Additional file 1. AIC as a function of $\mathrm{n}$ (degree of polynomial function) and $m$ (degree of trigonometric functions) (see text) for the position time series at site 0437, whose location is shown in Fig. $1 \mathrm{~b}$. The contour interval is -40 . We estimate the optimal $n$ and $m$ that minimize AIC.

Additional file 2. Examples of detrended data. The left-hand side shows the original east-west position time series, while the right-hand side shows the detrended east-west data. The unit is $\mathrm{cm}$. The location of each station is shown in Fig. 1b. The detrended data are not averaged over three days. (a) Site 1126. (b) Site 0466

Additional file 3. Ground displacement rates per year for three periods: 2012/1-2013/3, 1998/1-2000/1 and 2000/1-2002/1. The locations of GNSS sites are shown in the bottom.

Additional file 4. Contour map of the log likelihood of the system of the square-root information filter. The horizontal axis shows the logarithm of the temporal smoothing hyperparameter $\tau$, while the vertical axis shows the logarithm of the spatial smoothing hyperparameter $\lambda$. The contour interval is 20 .

Additional file 5. (A) Trend velocity estimated for the period between January 2012 and March 2013. Black and white arrows indicate observation and computation values from the estimated slip deficit rates, respectively. (B) Slip deficit rates (red arrows) estimated by applying the method of Yabuki and Matsu'ura (1992) to the data in (A). Broken lines indicate the iso-depth contours of the upper surface of the Philippine Sea plate with a contour interval of $20 \mathrm{~km}$.

Additional file 6. Estimated aseismic moment ( $\mathrm{Nm}$ ) plotted against the number of earthquakes. Aseismic moments are computed on the three segments denoted by blue dashed lines shown in Fig. 4h. The number of earthquakes within $5 \mathrm{~km}$ from each segment is indicated. (A) corresponds to the northernmost segment in Fig. 4h. (B) corresponds to the middle segment in Fig. 4h. (C) corresponds to the southernmost segment in Fig. $4 \mathrm{~h}$.

Additional file 7. (A) $\triangle$ CFS calculated from the aseismic slip for the period between January 2013 and May 2014 assuming a rigidity of 30 $\mathrm{GPa}$, Poisson's ratio of 0.25 , and a friction coefficient of 0.2 . The rake angle is opposite the motion of the Philippine Sea plate. The red arrows indicate the aseismic slip. (B) $\triangle$ CFS calculated from the aseismic slip for the period between July 2015 and February 2016. The nomenclature is the same as that of (A). (C) $\triangle C F S$ calculated from the total aseismic slip for the entire period in this study. Stars show the epicenters of the 1996 Hyuga-nada earthquakes. The nomenclature is the same as that of (A). $\triangle$ CFS is shown in areas adjacent to the aseismic slip area since we cannot calculate $\triangle$ CFS in aseismic slip areas.

\section{Abbreviations}

GNSS: global navigation satellite system; $M_{w}$ : moment magnitude; GSI: Geospatial Information Authority of Japan; AIC: Akaike's information criterion; $\triangle C F S$ : change in Coulomb failure stress.

\section{Acknowledgements}

We are grateful to our colleagues for helpful discussions. The hypocenter data of the low-frequency earthquakes are obtained from Japan Meteorological Agency. The data used in this paper are available by contacting ozawa-s96sa@ mlit.go.jp.

\section{Competing interests}

The author declares that he has no competing interests.

\section{Publisher's Note}

Springer Nature remains neutral with regard to jurisdictional claims in published maps and institutional affiliations.

Received: 26 October 2016 Accepted: 8 April 2017

Published online: 21 April 2017

\section{References}

Akaike H (1974) A new look at the statistical model identifications. IEEE Trans Autom Control Ac 19:716-723

Asano K, Iwata T (2016) Source rupture processes of the foreshock and mainshock in the 2016 Kumamoto earthquake sequence estimated from the kinematic waveform inversion of strong motion data. Earth Planets Space 68:147. doi:10.1186/s40623-016-0519-9

GSI (2015) Crustal movements in the Chugoku and Shikoku districts, Japan. Coord Commit Eq Pred 94:333

GSI (2016) Crustal movements in the Kinki district, Japan. Coord Commit Eq Pred 95:296

Harris R (1998) Introduction to special section: stress triggers, stress shadows, and implications for seismic hazard. J Geophys Res 103(B10):2434724358. doi:10.1029/98JB01576

Hirose H, Obara K (2005) Repeating short-and long-term slow slip events with deep tremor activity around the Bungo channel region, southwest Japan. Earth Planets Space. doi:10.1186/BF03351875

Hirose H, Hirahara K, Kimata F, Fujii N, Miyazaki S (1999) A slow thrust slip event following the two 1996 Hyuga-nada earthquakes beneath the Bungo Channel, southwest Japan. Geophys Res Lett 26:3237-3240

Hirose F, Nakajima J, Hasegawa A (2008) Three-dimensional seismic velocity structure and configuration of the Philippine Sea slab in southwest Japan estimated by double-difference tomography. J Geophys Res 113:19782012. doi:10.1029/2007JB005274

Kitagawa G, Gersch W (1996) Smoothness priors analysis of time series. In: Lecture Notes in Statistics, vol. 116, 261 pp., Springer, New York

Kobayashi A (2014) A long-term slow slip from 1996 to 1997 in the Kii channel, Japan. Earth Planets Space. doi:10.1186/1880-5981-66-9

Kumagai H (1996) Time sequence and the recurrence models for large earthquakes along the Nankai Trough revisited. Geophys Res Lett 23:1139-1142

Loveless J, Meade BJ (2010) Geodetic imaging of plate motions, slip rates, and partitioning of deformation in Japan. J Geophys Res 115:B02410. doi:10.1029/2008B006248

McGuire JJ, Segall P (2003) Imaging of aseismic slip transients recorded by dense geodetic networks. Geophys J Int 155:778-788

Nakagawa H, Miyahara B, Iwashita C, Toyofuku T, Kotani K, Ishimoto M, Munekane H, Hatanaka Y (2008) New analysis strategy of GEONET. In: Proceedings of international symposium of GPS/GNSS, Tokyo

Nishimura T, Ochi T (2015) Change of deformation rate at continuous GNSS stations in southwest Japan. Paper presented at the 124th fall meeting of the geodetic society of Japan, Kyushu University, Fukuoka, 41 (in Japanese)

Obara K (2002) Nonvolcanic deep tremor associated with subduction in southwest Japan. Science 296:1679. doi:10.1126/science.1070378 
Ozawa S (2014) Shortening of recurrence interval of Boso slow slip events in Japan. Geophys Res Lett 41:2762-2768. doi:10.1002/2014GL060072

Ozawa S, Murakami M, Tada T (2001) Time-dependent inversion study of the slow thrust event in the Nankai trough subduction zone, southwest Japan. J Geophys Res 106:787-802

Ozawa S, Murakami M, Kaidzu M, Tada T, Sagiya T, Hatanaka Y, Yarai H, Nishimura T (2002) Detection and monitoring of ongoing aseismic slip in the Tokai region, central Japan. Science 298:1009-1012

Ozawa S, Nishimura T, Suito H, Kobayashi T, Tobita M, Imakiire T (2011) Coseismic and postseismic slip of the 2011 magnitude-9 Tohoku-Oki earthquake. Nature 475:373-376

Ozawa S, Nishimura T, Munekane H, Suito H, Kobayashi T, Tobita M, Imakiire T (2012) Preceding, coseismic, and postseismic slips of the 2011 Tohoku earthquake, Japan. J Geophys Res. doi:10.1029/2011JB009120

Ozawa S, Yarai H, Imakiire T, Tobita M (2013) Spatial and temporal evolution of the long-term slow slip in the Bungo Channel, Japan. Earth Planets Space 65:67-73. doi:10.5047/eps.2012.06.009

Ozawa S, Tobita M, Yarai H (2016) A possible restart of an interplate slow slip adjacent to the Tokai seismic gap in Japan. Earth Planets Space 68:54. doi:10.1186/s40623-016-0430-4

Radiguet $\mathrm{H}$ et al (2016) Triggering of the 2014 Mw7.3 Papanoa earthquake by a slow slip event in Guerrero, Mexico. Nat Geosci 9:829-833. doi:10.1038/ ngeo2817
Sella GF, Dixon TH, Mao A (2002) REVEL: a model for recent plate velocities from space geodesy. J Geophys Res 107:B4. doi:10.1029/2000JB000033

Shiono K, Mikumo T, Ishikawa Y (1980) Tectonics of the Kyushu-Ryukyu arc as evidenced from seismicity and focal mechanisms of shallow to intermediate depth earthquakes. J Phys Earth 28:17-43

Simon D, Simon DL (2006) Kalman filtering with inequality constraints for turbofan engine health estimation. IEEE Proc Control Theory Appl 153:371-378

Takagi R, Obara K, Maeda T (2016) Slow slip event within a gap between tremor and locked zones in the Nankai subduction zone. Geophys Res Lett 43:1066-1074. doi:10.1002/2015GL066987

Yabuki T, Matsu'ura M (1992) Geodetic data inversion using a Bayesian information criterion for spatial distribution of fault slip. Geophy J Int 109:363-375

Yagi Y, Kikuchi M, Yoshida S, Sagiya T (1999) Comparison of the coseismic rupture with the aftershock distribution in the Hyuganada earthquakes of 1996. Geophys Res Lett 26:3161-3164

Yarai H, Munekane H (2015) Long-term slow slip events beneath the Kyushu Island, Japan. 124th Fall Meeting of the Geodetic Society of Japan, 44 (in Japanese)

Yarai H, Ozawa S (2013) Quasi-periodic slow slip events in the afterslip area of the 1996 Hyuga-nada earthquakes, Japan. J Geophys Res Solid Earth 118:2512-2527. doi:10.1002/jgrb.50161

\section{Submit your manuscript to a SpringerOpen ${ }^{\circ}$ journal and benefit from:}

- Convenient online submission

- Rigorous peer review

- Immediate publication on acceptance

- Open access: articles freely available online

- High visibility within the field

- Retaining the copyright to your article 